\title{
Chromosomal location of rDNA clusters and TTAGG telomeric repeats in eight species of the spittlebug genus Philaenus (Hemiptera: Auchenorrhyncha: Aphrophoridae)
}

\author{
ANNA MARYAŃSKA-NADACHOWSKA ${ }^{1}$, VALENTINA G. KUZNETSOVA² and TATYANA V. KARAMYSHEVA ${ }^{3}$ \\ ${ }^{1}$ Institute of Systematics and Evolution of Animals, Polish Academy of Sciences, Kraków, Poland; \\ e-mail: maryanska@isez.pan.krakow.pl \\ ${ }^{2}$ Zoological Institute of the Russian Academy of Sciences, Saint-Petersburg, Russia; e-mail: karyo@zin.ru \\ ${ }^{3}$ Institute of Cytology and Genetics, Siberian Branch of the Russian Academy of Sciences, Novosibirsk, Russia; \\ e-mail: kary@bionet.nsc.ru
}

Key words. Philaenus, Aphrophoridae, Auchenorrhyncha, FISH, Ag-NOR, rDNA, telomeres

\begin{abstract}
A cytogenetic investigation was performed in eight species of the spittlebug genus Philaenus using silver-NOR (AgNOR)-banding and fluorescence in situ hybridization (FISH) with $18 \mathrm{~S}$ rDNA and (TTAGG) ${ }_{n}$ telomeric probes. This is the first application of FISH technique in the Auchenorrhyncha, a suborder of the Hemiptera. FISH along with the rDNA probe revealed differences between species in the number and chromosomal location of major ribosomal RNA gene sites, the so-called nucleolar organizer regions (NORs). However, we found a lack of perfect correlation between the results of AgNOR-staining and rDNA-FISH in the detection of NORs. FISH with the telomeric probe confirmed that the chromosome ends of the Philaenus species are composed of the (TTAGG) ${ }_{n}$ nucleotide sequence, which is a common motif of insect telomeres.
\end{abstract}

\section{INTRODUCTION}

The chromosomes of Auchenorrhyncha have been studied cytologically for over 100 years (see Halkka, 1959), although they are not particularly amenable to cytological investigation, being holokinetic and hard to differentiate in a karyotype. Some progress toward the identification of separate marker chromosomes in the karyotypes of holokinetic groups was achieved using differential staining techniques (different types of chromosome banding); however, only a few publications of this kind have addressed Auchenorrhyncha specifically to date (Perepelov et al., 2002; Kuznetsova et al., 2003, 2009, 2010; Maryańska-Nadachowska et al., 2008, 2012). During the past few decades, fluorescence in situ hybridization (FISH) has become an important method in insect comparative cytogenetics. This technique allows genes or DNA sequences to be directly located on chromosomes in cytological preparations, although as yet, no such data are available for Auchenorrhyncha.

In Auchenorrhyncha, there are a few genera in which the chromosome number has been subjected to change during the course of speciation, a prime example being the spittlebug genus Philaenus (Maryańska-Nadachowska et al., 2012). Presently, a total of eight species are recognized in this genus, including the Mediterranean species, P. tesselatus, P. loukasi, P. arslani, P. signatus, $P$. maghresignus, $P$. tarifa, and $P$. italosignus, and the Holarctic species P. spumarius (Drosopoulos \& Remane, 2000). While the Mediterranean species are sympatric with $P$. spumarius, they are partially allopatric with one another. Mainly due to the outstanding dorsal colour polymorphism, the genus Philaenus has long received the widespread attention of biologists. Among other aspects, several studies have dealt with chromosome and molecular analyses of this group (Kuznetsova et al., 2003; Maryańska-Nadachowska et al., 2008, 2010, 2011, 2012; Seabra et al., 2010). Molecular analysis has confirmed the monophyly of the genus and the species status of all species with the exception of $P$. tesselatus, which has been suggested as representing a geographical and morphological form of $P$. spumarius (Maryańska-Nadachowska et al., 2010, 2011). Cytogenetic analysis using standard staining, C-banding, AgNOR-banding, and fluorochrome banding $\left(\mathrm{CMA}_{3}\right.$ and DAPI) revealed that the species differ from one another in terms of chromosome number, sex chromosome system and certain other characters. Altogether, three different chromosome numbers $(2 \mathrm{n}=$ 20,23 , and 24 for males) and three variations of the male sex chromosome system (X0, XY, and $\mathrm{X}_{1} \mathrm{X}_{2} \mathrm{Y}$ ) have been established in the genus Philaenus (Maryańska-Nadachowska et al., 2012).

The present study represents part of an ongoing project exploring the genus Philaenus. Here, we applied FISH with an $18 \mathrm{~S}$ rDNA probe to investigate eight Philaenus species. Our aim was to identify additional chromosome markers for a comparative study of representatives of the genus. Similarly, we examined the presence of TTAGG telomeric repeats in Philaenus species using FISH. So far, the only study to have reported the presence of (TTAGG) ${ }_{n}$ sequence in the genome of Calligypona pellucida (Delphacidae) is that of Frydrychová et al. (2004). Our study is thus the first cytogenetic investigation of Auchenorrhyncha using the FISH technique. 
Table 1. Species, collection localities, number of males and host plants of the eight Philaenus species studied.

\begin{tabular}{lccc}
\hline Species & Data and locality of collection & No. of males examined & Host plants \\
\hline P. spumarius & July 2007, Bieszczady Mts, SE Poland & 7 & polyphagous \\
P. tesselatus & June 2005; S Portugal & 7 & polyphagous \\
P. loukasi & August 2004 and July 2005; mountains in Greece & 8 & Eryngium sp. \\
P. arslani & June-July 2005 Mazraat Kfar Zebiani (Kesrouane), Lebanon & 5 & Eryngium sp. \\
P. italosignus & May 2002 and 2006; Sicily, Italy & 12 & Asphodelus aestivus \\
P. maghresignus & June 2005; S Spain & 6 & A. aestivus \\
P. signatus & August 2005; July 2008; central Greece & 8 & A. aestivus \\
P. tarifa & June 2005; S Spain & 6 & A. aestivus \\
\hline
\end{tabular}

\section{MATERIAL AND METHODS}

Eight Philaenus Stål, 1864 species were used in the present study. Specimens of seven species ( $P$. tesselatus Melichar, 1889; P. loukasi Drosopoulos \& Asche, 1991; P. arslani AbdulNour \& Lahoud, 1996; $P$. signatus Melichar, 1896; $P$. maghresignus Drosopoulos \& Remane, 2000; P. tarifa Remane \& Drosopoulos, 2001; and P. italosignus Drosopoulos \& Remane, 2000) were collected during the 2002-2010 field seasons in the Mediterranean region, while specimens of $P$. spumarius (Linnaeus, 1758) originated from Poland. The species collection sites and host plants as well as the number of specimens studied are given in Table 1 . On capture, insects were immediately fixed in Carnoy fixative (3 parts of $96 \%$ alcohol, 1 part of glacial acetic acid) and stored at $-15^{\circ} \mathrm{C}$ until required. Preparations were made from testes, which were dissected in a drop of $45 \%$ acetic acid and squashed under a coverslip on a glass microscope slide. The slides were frozen using dry ice, the coverslips were removed with a razor blade, and the preparations then air dried.

\section{Ag-staining}

Silver staining was performed following the technique of Howell \& Black (1980). Slides were treated in 50\% silver nitrate $\left(\mathrm{AgNO}_{3}\right)$ with gelatin as the developer in a moist chamber at $65^{\circ} \mathrm{C}$ for $8 \mathrm{~min}$. After the preparations had been stained appropriately, the reaction was stopped by rinsing three times with water, and the preparations air dried.

\section{Fluorescence in situ hybridization (FISH) with $18 \mathrm{~S}$ rDNA and (TTAGG) ${ }_{n}$ telomeric probes}

For rDNA-FISH, a $1.8 \mathrm{~kb}$ fragment of $18 \mathrm{~S}$ rDNA was generated by PCR using genomic DNA isolated from the specimens of Phyrrocoris apterus as a template. Amplification was performed in a final volume of $25 \mu \mathrm{l}$ containing $1.5 \mathrm{mM} \mathrm{MgCl}_{2}, 2.5$ mM dNTPs, $10 \mu \mathrm{M}$ of both the 18 Sai forward primer (5'-CCT GAG AAA CGG CTA CCA CAT C-3') and the 18Sbi reverse primer (5'-GAG TCT CGT TCG TTA TCG GA-3') (Whiting et al., 1997), $100 \mathrm{ng}$ template DNA, and 5 U Taq DNA polymerase (Qiagen, Hilden, Germany). An initial denaturation period of 3 min at $94^{\circ} \mathrm{C}$ was followed by 30 cycles of $60 \mathrm{~s}$ at $94^{\circ} \mathrm{C}$, annealing for $60 \mathrm{~s}$ at $51^{\circ} \mathrm{C}$, a $1.5 \mathrm{~min}$ extension step at $72^{\circ} \mathrm{C}$, and concluded with a final extension step of $10 \mathrm{~min}$ at $72^{\circ} \mathrm{C}$. The probe was labelled by nick translation with digoxigenin-11dUTP (Roche Diagnostics GmbH, Germany).

The (TTAGG) ${ }_{n}$ telomeric probe was generated by PCR using a modified version of the López-Fernández et al. (2004) technique. PCR was performed in $50 \mu 1$ of reaction mixture containing $1.5 \mathrm{mM} \mathrm{MgCl}_{2}, 0.2 \mathrm{mM}$ of each dNTP, $0.5 \mu \mathrm{M}$ of each of the two primers (5'-GGTTA-GGTTA-GGTTA-GGTTAGG-3' and 5'-TAACC-TAACC-TAACC-TAACC-TAA-3'), and $2 \mathrm{U}$ Taq DNA polymerase. A control PCR run lacking any DNA template was performed with an initial cycle of $90 \mathrm{~s}$ at $94^{\circ} \mathrm{C}$, followed by 30 cycles of $45 \mathrm{~s}$ at $94^{\circ} \mathrm{C}, 30 \mathrm{~s}$ at $40^{\circ} \mathrm{C}$, and $60 \mathrm{~s}$ at $72^{\circ} \mathrm{C}$, and a final extension step of $10 \mathrm{~min}$ at $72^{\circ} \mathrm{C}$. The PCR product was then labelled with digoxigenin-11-dUTP during additional PCR cycles.

For FISH with both rDNA and telomeric probes, we used the procedure described in Lichter et al. (1988). Chromosome preparations were treated with $100 \mu \mathrm{g} / \mathrm{ml}$ RNase A. After denaturation, the chromosomes were hybridized with a probe mixture containing $20 \mathrm{ng}$ of $18 \mathrm{~S}$ rDNA probe, $20-50 \mathrm{ng}$ telomeric probe $\left(\right.$ TTAGG) ${ }_{n}$ and $10 \mu \mathrm{g}$ of sonicated salmon sperm DNA (Invitrogen, Life Technologies Inc., San Diego, CA, USA). Hybridization signals were detected with avidin-Alexa 488 (Invitrogen) and mouse anti-digoxigenin antibodies conjugated to Cy3-IgG (Jackson Immuno Research Laboratories, West Grove, PA, USA). The preparations were counterstained with 2 $\mu 1 / \mathrm{ml}$ DAPI (4'-6'-diamidino-2-phenyolindole) (Sigma-Aldrich, St. Louis, MO, USA) for $15 \mathrm{~min}$ and then mounted in an antifade based on DABCO (1-4-diazabicyclo[2.2.2] octane; SigmaAldrich) (see Sahara et al., 1999). At least 10 meiotic divisions (diplotene/ diakinesis) per male and 5 to 12 males per species were analyzed using the FISH and $\mathrm{AgNO}_{3}$ techniques (Table 1). Photographs were taken with a Nikon Eclipse 400 light microscope fitted with a CCD DS-U1 camera using Chroma filter sets (for FISH). Lucia Image 5.0 software was applied and images were processed in Adobe Photoshop Elements 9.

\section{RESULTS}

\section{Standard karyotypes}

In agreement with our previous results (MaryańskaNadachowska et al., 2012), the eight studied Philaenus species showed karyotypes with a male meiotic formula of $\mathrm{n}=11+\mathrm{X} 0$ in P. spumarius and P. tesselatus, $\mathrm{n}=9+$ neo-XY in $P$. loukasi and $P$. arslani, $\mathrm{n}=11+$ neo-XY in $P$. signatus, $P$. maghresignus, and $P$. tarifa, and $\mathrm{n}=10+$ neo-neo- $\mathrm{X}_{1} \mathrm{X}_{2} \mathrm{Y}$ in $P$. italosignus (Figs 1-22).

\section{Detection of a tandem telomeric repeat sequence by FISH with a (TTAGG) ${ }_{n}$ probe}

In each of the species studied, bright fluorescent signals were seen at the ends of spermatocyte chromosomes (Figs $2,5,7,9,12,14,15,18,21,22)$. These findings indicate conclusively that the telomeres in Philaenus species are composed of the (TTAGG) ${ }_{n}$ nucleotide sequence.

\section{Location and activity of ribosomal genes revealed by FISH with an $18 S$ rDNA probe and silver staining}

A difference in ribosomal gene locations was found between $P$. spumarius and $P$. tesselatus, which share a common chromosomal complement $(2 \mathrm{n}=22+\mathrm{X})$. In $P$. 

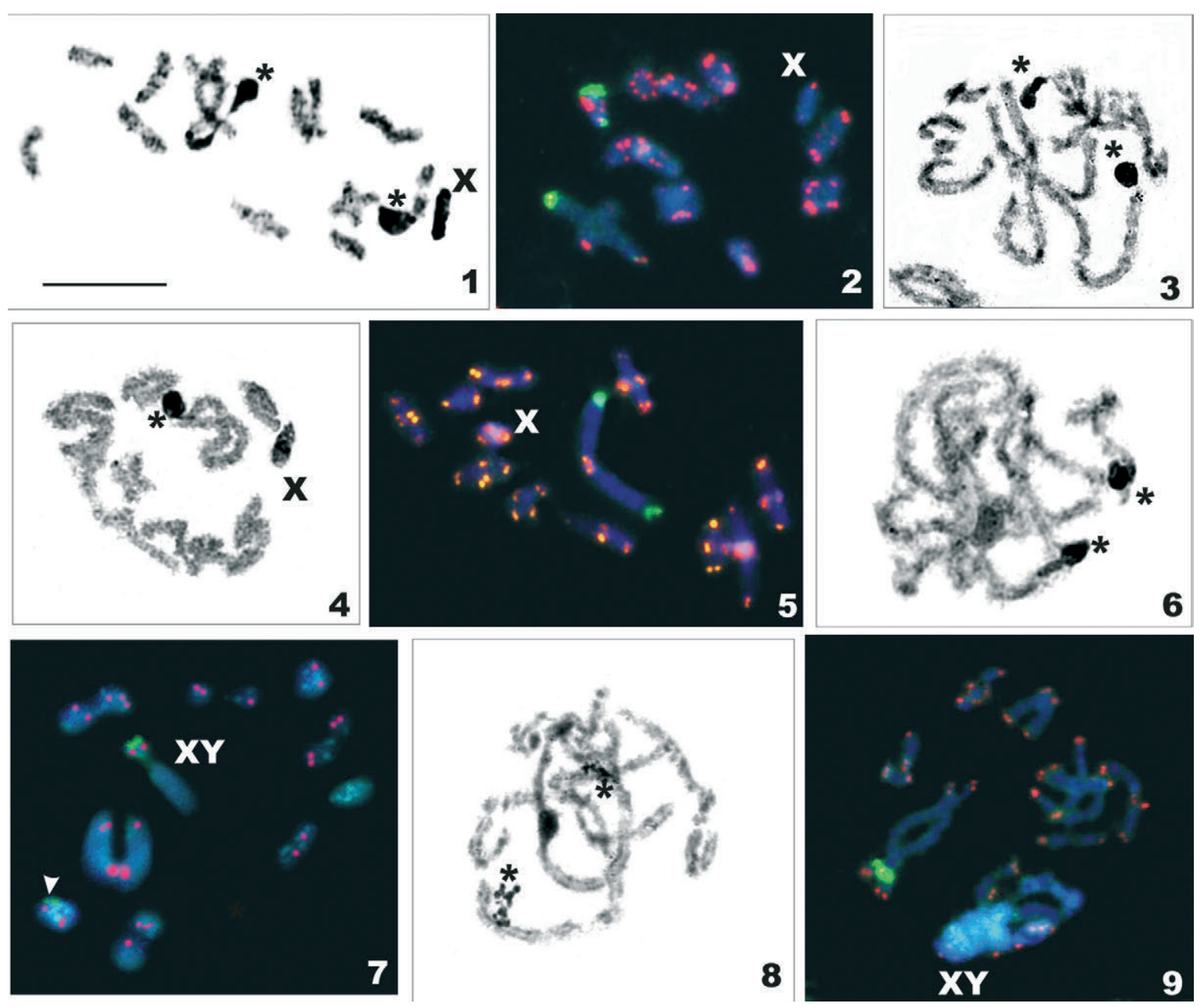

Figs 1-9. Chromosomal locations of Ag-positive sites (asterisks; Figs 1, 3, 4, 6, 8), clusters of 18S rDNA (green signals; Figs 2, 5, 7, 9) and TTAGG telomeric repeats (red signals; Figs 2, 5, 7,9) in males of Philaenus species. 1 and 2: P. spumarius. 1 - diplotene with Ag-positive sites in the largest bivalent and in a medium-sized bivalent; 2 - diakinesis with two rDNA signals in the same two bivalents (signals in the largest bivalent are heteromorphic in size). 3-5: P. tesselatus. 3 - pachytene with Ag-positive sites in the largest bivalent and in one of the smaller bivalents; 4 - diplotene with the only Ag-positive site in the largest bivalent; 5 - diakinesis with two rDNA signals in opposite ends of the largest bivalent. 6 and 7: P. loukasi. 6 - pachytene with Ag-positive sites, one in the largest bivalent and the other of uncertain location; 7 - diakinesis with rDNA signals in the Y chromosome of the neo-XY bivalent and in a medium-sized bivalent (arrowhead). 8 and 9: P. arslani. 8 - pachytene with two Ag-positive sites, one (interstitial) in the largest bivalent and the other of uncertain location; 9 - diplotene with the only interstitial rDNA signal in the largest bivalent. Bar = $10 \mu \mathrm{m}$.

spumarius, the silver staining of male meiotic cells labelled NORs in the largest pair of autosomes (no. 1) as well as in the medium-sized pair (presumed no. 6) (Fig. 1). The FISH experiments confirmed the presence of rDNA arrays in the same bivalents (Fig. 2). In P. tessela$t u s$, silver staining predominantly detected Ag-positive sites in the autosome pair no. 1. However, an additional Ag-positive site was occasionally observed in a mediumsized bivalent (presumed pair no. 6) in some cells (Figs 3 and 4). In contrast to silver staining, FISH experiments performed in this species invariably showed $18 \mathrm{~S}$ rDNA only in the largest pair of autosomes (Fig. 5). In both species, rDNA clusters (i.e. NORs) were located terminally. Hybridization signals were uniform in size and intensity with the exception of the large NOR-bivalent in $P$. spumarius, which was constantly heteromorphic for the size of the signals (Fig. 2).
In yet another pair of species sharing the same gross structure of karyotype, $P$. loukasi and $P$. arslani $(2 \mathrm{n}=18$ + neo-XY), a difference between ribosomal gene locations was also found. In P. loukasi, silver staining revealed two Ag-positive regions in male meiotic cells (Fig. 6). Unfortunately, exact identification of the NORbearing chromosomes was not possible with silver staining. rDNA-FISH clearly detected a bright signal on the Y chromosome in the neo-XY bivalent and a weak signal on one of the medium-sized pairs of autosomes (presumed no. 6) (Fig. 7). The signals were seen close to the ends of the NOR-chromosomes. In P. arslani, silver staining likewise revealed two Ag-positive regions in male meiotic cells, one of them being of uncertain location, the other one clearly belonging to the largest pair of autosomes (Fig. 8). However, using rDNA-FISH the only signal was observed on the largest autosome bivalent (Fig. 9). The 


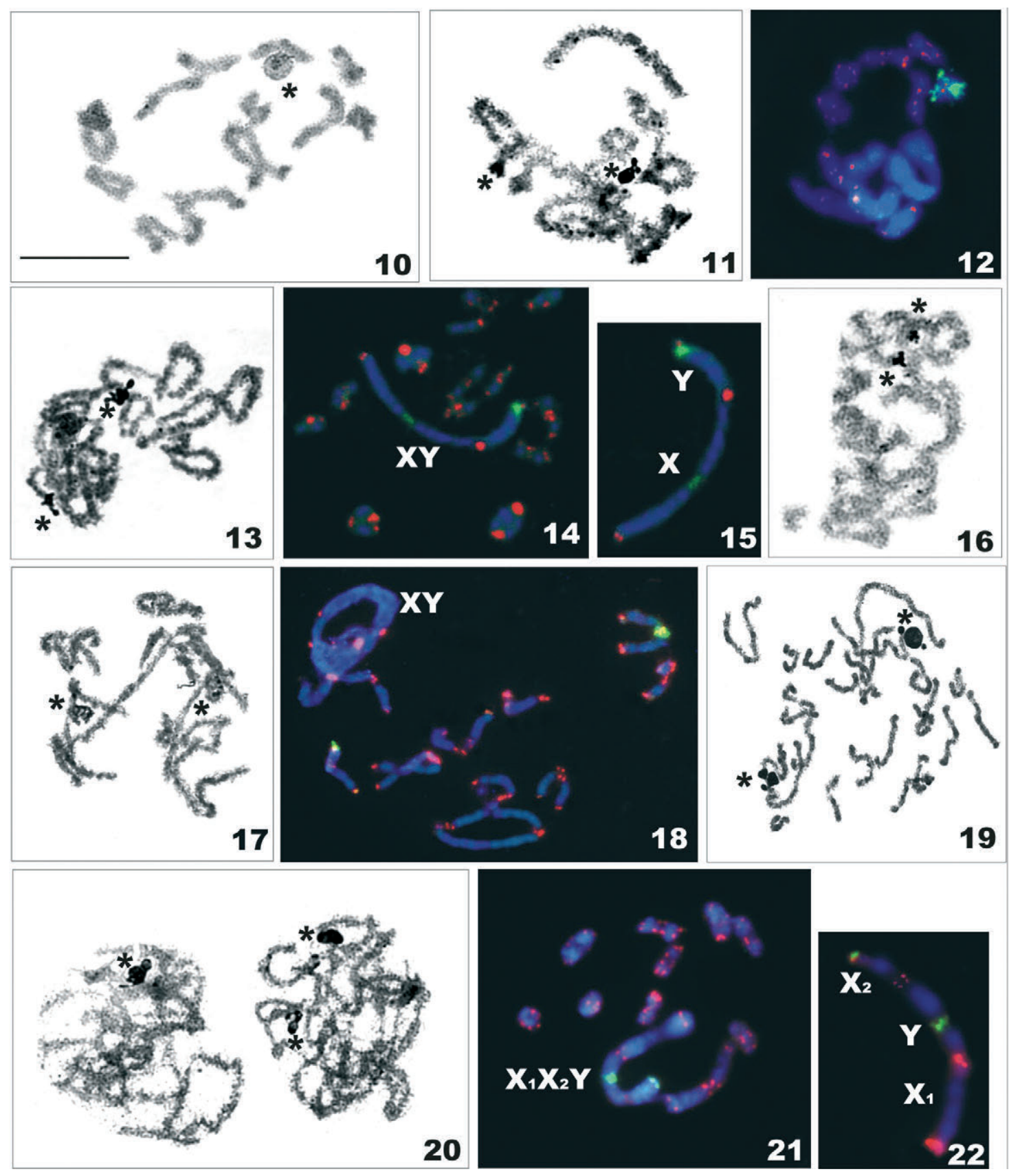

Figs 10-22. Chromosomal locations of Ag-positive sites (asterisks; Figs 10, 11, 13, 16, 17, 19, 20), clusters of 18S rDNA (green signals; Figs 12, 14, 15, 18, 21, 22) and TTAGG telomeric repeats (red signals; Figs 12, 14, 15, 18, 21, 22) in males of Philaenus species. 10-12: P. signatus. 10 and 11 - two diplotenes, one with one Ag-positive site in a medium-sized bivalent (Fig. 10), and the other with two Ag-positive sites, one in the largest bivalent and the other of uncertain location (Fig. 11); 12 - diakinesis with the only rDNA signal in a medium-sized bivalent. 13-15: P. maghresignus. 13 - diplotene with two Ag-positive sites; 14 - diakinesis with two rDNA signals in the sex-chromosome bivalent, one terminal in the neo-Y chromosome and the other interstitial in the neo-X chromosome; 15 - a detail of the XY sex chromosome bivalent with two rDNA signals. 16-18: P. tarifa. 16 - mitotic prophase with two Ag-positive sites; 17 - diplotene with two Ag-positive sites; 18 - diakinesis with rDNA signals in the largest bivalent and in a medium-sized bivalent. 19-22: P. italosignus. 19 - mitotic prophase (silver-staining) with two Ag-positive sites; 20 - two pachytenes (silver-staining) with the only (left) and with two (right) Ag-positive sites; 21 - diakinesis/metaphase I with two rDNA signals in the sex chromosome trivalent, one terminal in the neo- $\mathrm{X}_{2}$ chromosome and the other interstitial in the neo-Y chromosome; 22 - a detail of the $\mathrm{X}_{1} \mathrm{X}_{2} \mathrm{Y}$ sex chromosome trivalent with two rDNA signals. Bar $=10 \mu \mathrm{m}$ (not applicable for the enlarged images in Figs 15 and 22).

special feature of this karyotype is that the rDNA array is most probably subterminal, being universally seen at a short distance from the end of the NOR-chromosome, as evidenced by both silver-staining and FISH (Figs 8, 9).
In $P$. signatus, $P$. maghresignus, and $P$. tarifa, another three species sharing a common chromosomal complement $(2 \mathrm{n}=22+$ neo-XY), an essential difference in ribosomal gene location was found. In P. signatus, silver 


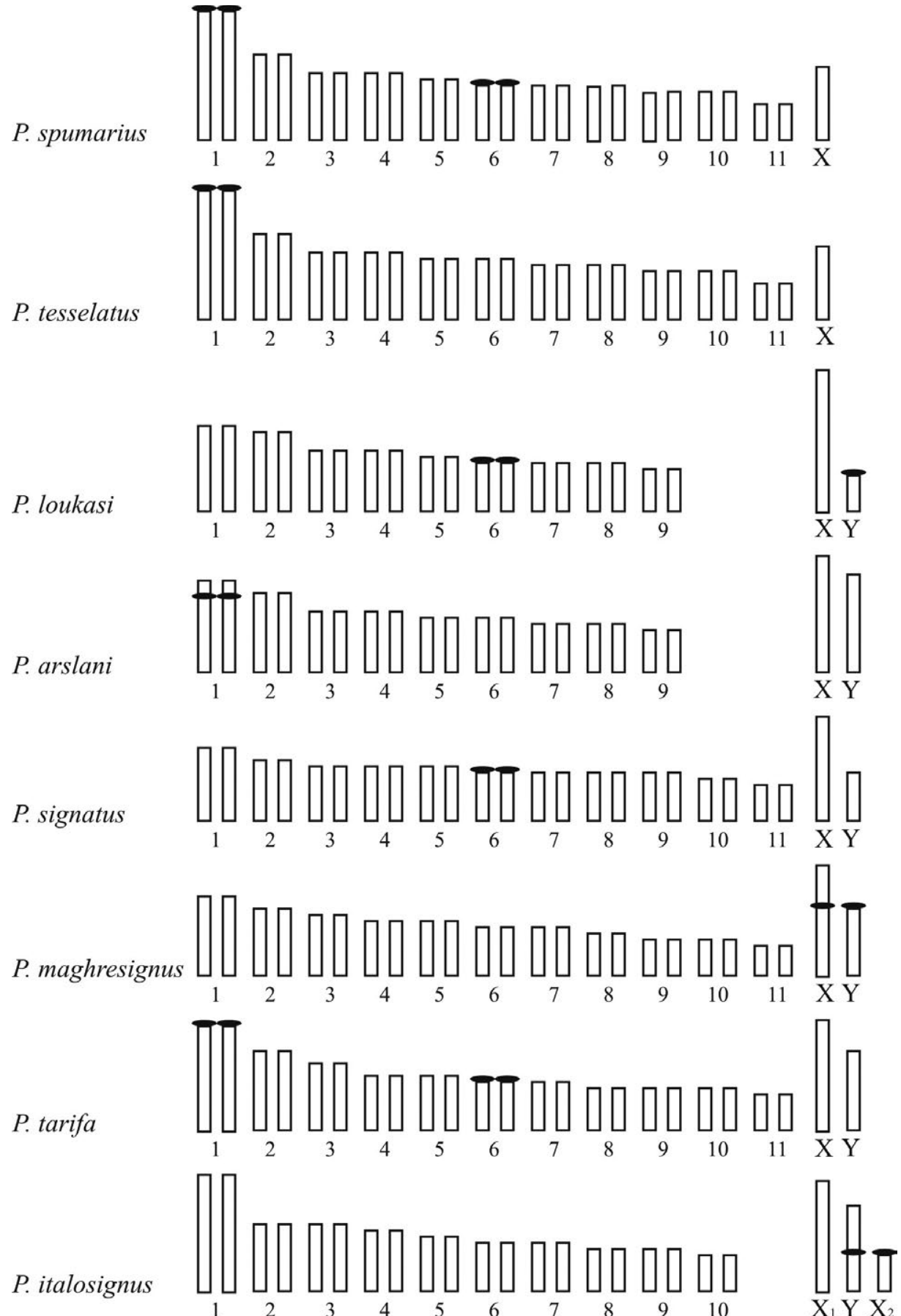

Fig. 23. Schematic view of rDNA positions (black lenticular bodies) in karyotypes of eight Philaenus species according to the results of rDNA-FISH.

staining revealed one (Fig. 10), or sometimes two (Fig. 11), Ag-positive sites in prophase I meiotic cells. One of the sites was always located in a medium-sized bivalent, whereas the location of the other site, when present, was not reliably identified. rDNA-FISH invariably detected a single rDNA array in one of the medium-sized bivalents, probably no. 6 (Fig. 12). In P. maghresignus, two silverpositive sites were seen in pachytene cells (Fig. 13). rDNA-FISH detected rDNA arrays in the sex chromosome bivalent, in which one signal was terminal in the neo-Y chromosome, while the other was interstitial in the
neo-X chromosome (Figs 14, 15). In $P$. tarifa, silver staining revealed a single pair of NOR-chromosomes in mitotic prophases (Fig. 16); however, two autosome bivalents showed AG-positive sites in meiotic cells (Fig. 17). rDNA-FISH revealed two rDNA clusters in this karyotype, one located in the larger (probably the largest) bivalent, the other one in a medium-sized bivalent, probably no. 6 (Fig. 18).

In P. italosignus $\left(2 \mathrm{n}=20+\mathrm{X}_{1} \mathrm{X}_{2} \mathrm{Y}\right)$, two chromosomes with Ag-positive sites were found in mitotic prophases (Fig. 19). In meiotic prophases, one or sometimes two, 
Ag-positive sites were observed (Fig. 20). The 18S rDNA probe localized two clusters in the sex chromosome trivalent in meiotic cells; one of these signals was terminal in the neo- $\mathrm{X}_{2}$, whereas the other was interstitial in the neo- $\mathrm{Y}$ chromosome (Figs 21, 22).

It is worth noting that the Ag-positive sites could be seen and identified only in the extended prophase chromosomes. At mitotic and meiotic prophases, argentophilic material was separated into interconnected granules grouped more commonly around particular (presumably NOR-bearing) chromosomes.

\section{DISCUSSION}

In the genus Philaenus, differences in chromosome number (Maryańska-Nadachowska et al., 2012; present paper) are largely in agreement with the recognized grouping proposed on the basis of morphology (Drosopoulos \& Remane, 2000) as well as being supported by larval food plant relationships (Drosopoulos, 2003). The species feeding on common asphodel, Asphodelus aestivus, that is, $P$. signatus, $P$. maghresignus, and $P$. tarifa, sharing $22+$ neo-XY, and $P$. italosignus, having $2 \mathrm{n}=20$ + neo-neo- $\mathrm{X}_{1} \mathrm{X}_{2} \mathrm{Y}$, are all similar in morphology and have the same or closely related karyotypes (that of $P$. italosignus has evidently arisen from $22+$ neo-XY via an additional fusion between the ancestral $\mathrm{Y}$ chromosome and an autosome pair). These species fall into the species group "signatus", defined on the basis of the morphology of male genitalia (Drosopoulos \& Remane, 2000). The species $P$. loukasi $(2 \mathrm{n}=18+$ neo-XY) and $P$. arslani $(2 \mathrm{n}$ $=18+$ neo-XY), whose larvae develop on host plants growing in arid conditions, share similar karyotypes, as do the polyphagous species $P$. spumarius $(2 \mathrm{n}=22+\mathrm{X})$ and $P$. tesselatus $(2 \mathrm{n}=22+\mathrm{X})$, feeding on a wide range of dicotyledonous plants. In turn, all of these Philaenus species fall into another morphologically substantiated group, "spumarius". In phytophagous insects, host plant shifting might be an important factor in sympatric divergence and speciation (Berlocher \& Feder, 2002; Horn et al., 2006; Loxdale, 2010). In some aphids, another group of the order Hemiptera, polymorphism for chromosome number was found to be correlated with change of host plants (Brown \& Blackman, 1988; De Barro et al., 1995; Hales et al., 2000). Such karyotypic divergence in relation to host plant is known to occur in the genus Amphorophora where $A$. idaei Börner, which feeds on raspberry (Rubus idaeus) has $2 \mathrm{n}=18$, whereas A. rubi (Kaltenbach), which feeds on blackberry (Rubus fruticosus agg.) has $2 \mathrm{n}=20$. These host-specific taxa are distinguishable morphologically using multivariate analysis and presently recognized as separate species (Blackman et al., 2000). Another example concerns the closely related forms of the corn-leaf aphid, Rhopalosiphum maidis (Fitch). In this species there is a strong association between chromosome number and host plant. Specimens with $2 \mathrm{n}=8$ are found on Sorghum and Zea mays, whereas on northern hemisphere barley, Hordeum vulgare, $2 \mathrm{n}=10$ is common (Brown \& Blackman, 1988).
With this assumption, we speculated that changes in the host-plant associations of Philaenus species may well be accompanied by chromosome rearrangements and that karyotype changes may have occurred independently several times in the evolution of the genus. Moreover, we inferred ways of chromosome rearrangement that probably occurred during the karyotype evolution of this group (Maryańska-Nadachowska et al., 2012). Assumptions of the sequence of karyotype rearrangements were, however, based on a limited set of characters, such as chromosome number, sex chromosome system, and chromosome size. Our present study was aimed to find additional markers in Philaenus (location of rDNA and telomeric DNA sequences revealed by FISH) for testing the validity of the aforementioned assumptions.

Indeed, 18S rDNA-FISH enabled us to detect differences in the number and location of ribosomal loci between the species, and more importantly, differences were found between species with the same chromosome number. Within the genus, three species ( $P$. tesselatus, $P$. arslani, $P$. signatus) were shown to have one cluster of rDNA genes, whereas five species ( $P$. spumarius, $P$. tarifa, P. italosignus, P. loukasi, P. maghresignus) had two clusters. In $P$. italosignus and $P$. maghresignus, rDNA sites are borne by sex chromosomes, whereas in the other species examined, by autosomes or (in P. loukasi) by both autosomes and the neo-Y chromosome (Fig. 23).

It is clear that the major rDNA distribution patterns show no correlation with the aforementioned grouping of the genus. Philaenus species evidently originate (monophyletically) from a common ancestor, as it has been confirmed by molecular analyses (Maryańska-Nadachowska et al., 2010, 2011). Differences as presently revealed suggest that karyotype changes may have occurred during species formation and evolved independently. At least four independent translocation events occurred in the evolution of the neo-XY system in Philaenus species. In P. loukasi, P. arslani, P. maghresignus, P. signatus, and $P$. tarifa, neo-sex chromosome systems possibly originated by fusion of a pair of autosomes with the original $\mathrm{X}$ chromosome, while in P. italosignus, the original neo-Y chromosome probably fused with the homologue of another autosomal pair, resulting in a neo-neo- $\mathrm{X}_{1} \mathrm{X}_{2} \mathrm{Y}$ (Maryańska-Nadachowska et al., 2012). Our present data suggest that the fused autosomes were different in every case, lacking NORs, as in P. signatus and P. tarifa, while retaining NORs in other species.

The differences observed between the very closely related $P$. spumarius and $P$. tesselatus are also noteworthy. Our molecular analyses using nucleotide sequences from two mitochondrial genes (COI and $C y t B)$ and one nuclear region (ITS 2) strongly support the species status of all species, the only exception being $P$. tesselatus, which may represent a geographical and morphological form of $P$. spumarius (Maryańska-Nadachowska et al., 2010, 2011). Even so, we found that these species were indeed different in that $P$. tesselatus had a single rDNA cluster in the largest autosome pair, whereas in $P$. spu- 
marius, the $18 \mathrm{~S}$ rDNA probe also mapped to the largest pair of autosomes and, in addition, to one of the mediumsized bivalents.

It is of interest that autosomally located rDNA sites, when present in the species studied, were situated similarly on the largest and/or on a medium-sized bivalent. Likewise, in P. loukasi one of the two loci was located on a medium-sized bivalent. By convention, the mediumsized NOR-bivalent, when present in a species, could be identified as belonging to chromosome pair no. 6 . Thus, it appears that the NOR-bearing medium-sized autosome pairs are homologues in different species. Be that as it may, the currently available chromosome markers are insufficient to test the validity of this hypothesis.

NOR-chromosomes in the species studied mostly showed terminally located rDNA clusters, but in some cases the clusters were clearly positioned in the interstitial position: in the neo-X of $P$. maghresignus, the neo-Y of $P$. italosignus, or in the autosomal NOR-bivalent of $P$. arslani. These interstitial patterns argue that some ancestral NOR-bearing autosomes were involved in fusions during Philaenus phylogenesis. In most species and specimens examined to date, hybridization signals were uniform in size and intensity; although two exceptions were observed. One of these exceptions was $P$. spumarius, in which the larger NOR-bivalent appears to be heteromorphic due to the size of the signals, while the other was $P$. loukasi, in which the signals on the Y chromosome and on the medium-sized pair of autosomes differed in intensity. Most probably the observed differences reflect variation in the copy number of rRNA genes either between different chromosome pairs or between two homologous chromosomes. This can be attributed to various mechanisms, including unequal crossing over, transposition, tandem amplification and other rearrangements involving homologous segments, yielding structural modification of NORs (Castro et al., 2001) The heteromorphism in size and intensity of NORs has been frequently reported in aphids (Monti et al., 2011 and reference therein), heteropterans (Grozeva et al., 2010), orthopterans (Warchałowska-Śliwa et al., 2009), as well as certain other insect orders.

It is generally accepted that NORs are often highlighted by fluorescent staining with chromomycin $\mathrm{A}_{3}\left(\mathrm{CMA}_{3}\right)$ that binds to GC-rich regions. In Philaenus species, we found that the position of the major rDNA sites corresponded in most cases to active Ag-NOR sites. Nevertheless, there were some rDNA-FISH clusters that were negative for Ag-NORs (as well as for the $\mathrm{CMA}_{3}$-NORs described in Maryańska-Nadachowska et al., 2012), and some Ag-positive regions that did not hybridize with the $18 \mathrm{~S}$ rDNA probe. For example, in $P$. tesselatus and $P$. arslani the majority of cells showed rDNA-FISH signals in the first bivalent but prominent argentophilic material was occasionally visible on a medium-sized bivalent as well. As shown in our previous study (MaryańskaNadachowska et al., 2012) $\mathrm{GC} / \mathrm{CMA}_{3}$-signals were found on the largest bivalent in the first species and on two bivalents in the second. The lack of correspondence between Ag,-NORs and $\mathrm{CMA}_{3}$, staining and rDNA sites has been reported in many animal species (Gromicho et al., 2005 and references therein), including insects such as ants (Lorite et al., 1997), beetles (Colomba et al., 2000) and grasshoppers (Vitturi et al., 2008). Thus, our data on Philaenus species support the view that not only NORs, but also some other regions, are stained with $\mathrm{CMA}_{3}$ and silver nitrate, and that some rDNA sites are not always detected using these techniques (Gromicho et al., 2005). Although our study represents the first application of FISH to Auchenorrhyncha chromosomes, it testifies that this approach is a potentially valuable tool for the physical mapping of major rDNA regions on the chromosomes of such insects.

We examined the presence of TTAGG telomeric repeats by using FISH in all species of Philaenus available to us. To date, a single attempt was made to detect telomeric repeats in Auchenorrhyncha chromosomes, this concerning the leafhopper, Calligypona pellucida (F.) (Delphacidae) (Frydrychová et al., 2004). This particular earlier study was, however, done using Southern hybridization of genomic DNA, a technique known to rank below FISH in terms of accuracy of telomeric repeat detection, since it reveals only the presence of the sequence in the genome, but not its location. Our FISH experiments with the (TTAGG) ${ }_{n}$ probe have shown that this sequence occurs at the ends of all chromosomes, providing conclusive evidence that in Philaenus species, telomeres consist of TTAGG tandem repeats. This telomere motif is present in the vast majority of evolutionary lineages of insects and other arthropods and is thought to represent an ancestral sequence of telomeres in the Arthropoda as a whole (Sahara et al., 1999; Frydrychová et al., 2004; Vítková et al., 2005; Lukhtanov \& Kuznetsova, 2010). Our data on eight species of the genus Philaenus suggest that the (TTAGG) ${ }_{n}$ telomeric repeat motif has been conserved in the Auchenorrhyncha.

ACKNOWLEDGEMENTS. The study was supported by project "Molecular cytogenetics and phylogeny of the order Hemiptera (Insecta)" within the research agreement between Russian Academy of Sciences and Polish Academy of Sciences, partially for V.G. Kuznetsova by the Russian Foundation for Basic Research (grant 11-04-00734), and programs of the Presidium of the Russian Academy of Sciences "Gene Pools and Genetic Diversity". We thank H.D. Loxdale for his helpful comments on the manuscript.

\section{REFERENCES}

Berlocher S.H. \& Feder J.L. 2002: Sympatric speciation in phytophagous insects: moving beyond controversy? - Annu. Rev. Entomol. 47: 773-815.

Blackman R.L., Spence J.M. \& Normark B.B. 2000: High diversity of structurally heterozygous karyotypes and rDNA arrays in parthenogenetic aphids of the genus Trama (Aphididae: Lachnidae). — Heredity 84: 254-260.

Brown P.A. \& Blackman R.L. 1988: Karyotype variation in the corn leaf aphid, Raphalosiphum maidis (Fitch), species complex (Hemiptera: Aphididae) in relation to host-plant and morphology. — Bull. Entomol. Res. 78: 351-363.

Castro J., Rodríguez S., Pardo B.G., SÁnchez L. \& Martínez P. 2001: Population analysis of an unusual NOR-site poly- 
morphism in brown trout (Salmo trutta L.). - Heredity $\mathbf{8 6}$ 291-302.

Colomba M.S., Vitturi R. \& Zunin M. 2000: Chromosome analysis and rDNA FISH in the stag beetle Dorcus parallelipipedus L. (Coleoptera: Scarabaeoidea: Lucanidae). Hereditas 133: 249-253.

De Barro P.J., Sherratt T.N., David O. \& Maclean N. 1995: An investigation of the differential performance of clones of the aphid Sitobion avenae on two host species. - Oecologia 104: 379-385.

Drosopoulos S. 2003: New data of the nature and origin of colour polymorphism in the spittlebug genus Philaenus (Hemiptera: Aphrophoridae). - Ann. Soc. Entomol. Fr. (n.s.) 39: $31-42$.

Drosopoulos S. \& Remane R. 2000: Biogeographic studies on the spittlebug species group Philaenus signatus with the description of two new allopatric species. - Ann. Soc. Entomol. Fr. (n.s.) 36: 269-277.

Frydrychová R., Grossman P., Trubač P., Vítková M. \& MAREC F. 2004: Phylogenetic distribution of TTAGG telomeric repeats in insects. - Genome 47: 163-178.

Gromicho M., Ozout-Costaz C. \& Collares-Pereira M.J. 2005: Lack of correspondence between CMA3-Ag-positive signals and $28 \mathrm{~S}$ rDNA loci in two Iberian minnows (Teleostei, Cyprinidae) evidenced by sequential banding. Cytogenet. Genome Res. 109: 507-511.

Grozeva S., Kuznetsova V.G. \& Anokhin B. 2010: Bed bug cytogenetics: karyotype, sex chromosome system, FISH mapping of $18 \mathrm{~S}$ rDNA, and male meiosis in Cimex lectularius Linnaeus, 1758 (Heteroptera: Cimicidae). - Compar. Cytogenet. 4: 151-160.

Hales D., Wilson A.C.C., Spence J.M. \& Blackman R.L. 2000: Confirmation that Myzus antirrhini (Macchiati) (Hemiptera: Aphididae) occurs in Australia, using morphometrics, microsatellite typing and analysis of novel karyotypes by fluorescence in situ hybridization. - Austral. J. Entomol. 39: $123-129$.

HalkKa O. 1959: Chromosome studies on the Hemiptera, Homoptera, Auchenorrhyncha. - Ann. Acad. Sci. Fenn. (A. IV. Biol.) 4: 1-71.

Horn A., Roux-Morabito G., Lieutier F. \& Kerdelhue C. 2006: Phylogeographic structure and past history of the circum Mediterranean species Tomocus destruens Woll (Coleoptera: Scolytinae). - Mol. Ecol. 15: 1603-1615.

HoweLL W.M. \& BLACK D.A. 1980: Controlled silver staining of nucleolus organizer regions with protective colloidal developer: a 1-step method. - Experientia 36: 1014-1015.

Kuznetsova V.G., Maryańska-Nadachowska A. \& Nokkala S. 2003: A new approach to the Auchenorrhyncha (Hemiptera, Insecta) cytogenetics: chromosomes of the meadow spittlebug Philaenus spumarius (L.) examined using various chromosome banding techniques. - Folia Biol. (Kraków) 51: 33-40.

KuZnetsova V.G., MaryańsKa-Nadachowska A. \& NokKala S. 2009: Karyotype characterization of planthopper species Hysteropterum albaceticum Dlabola, 1983 and Agalmatium bilobum (Fieber, 1877) (Homoptera: Auchenorrhyncha: Issidae) using AgNOR-, C- and DAPI/CMA3-banding techniques. - Comp. Cytogenet. 3: 111-123.

Kuznetsova V.G., Maryańska-Nadachowska A. \& Gnezdilov V.M. 2010: Meiotic karyotypes and testis structure of 14 species of the planthopper tribe Issini (Hemiptera: Fulgoroidea: Issidae). - Eur. J. Entomol. 107: 465-480.

Lichter P., Cremer T., Tang C.J., Watkins P.C., Manuelidis L. \& WARD D.C. 1988: Rapid detection of human chromosome 21 aberration by in situ hybridization. - Proc. Natl. Acad. Sci. USA 85: 9664-9668.
López-Fernández C., Pradillo E., Zabal-Augirre M., Fernandez J.L., Garcia de la Vega C. \& Gisalvez J. 2004: Telomeric and interstitial telomeric-like DNA sequence in Orthoptera genomes. - Genome 47: 757-763.

Lorite P., Aranega E., Luque F. \& Palomeque T. 1997: Analysis of the nucleolar organizing regions in the ant Tapinoma nigerrinum (Hymenoptera, Formicidae). - Heredity 78: $578-582$.

LOXDALE H.D. 2010: Rapid genetic changes in natural insect populations. - Ecol. Entomol. (Suppl. 1) 33: 155-164.

Lukhtanov V.A. \& Kuznetsova V.G. 2010: What genes and chromosomes say about the origin and evolution of insects and other arthropods. - Russ. J. Genet. 46: 1115-1121.

MaryańsKa-NadachowsKa A., KuZnetsova V.G. \& AbdulNouR H. 2008: A chromosomal study on the meadow spittlebug Philaenus arslani Abdul-Nour \& Lahoud, 1995 (Hemiptera, Auchenorrhyncha, Aphrophoridae) from Lebanon. Eur. J. Entomol. 105: 205-210.

Maryańska-Nadachowska A., Drosopoulos S., LachowsKa D., Kajtoch Ł. \& Kuznetsova V.G. 2010: Molecular phylogeny of the Mediterranean species of Philaenus (Hemiptera: Auchenorrhyncha: Aphrophoridae) using mitochondrial and nuclear DNA sequences. - Syst. Entomol. 35: 318-328.

MaryańsKa-Nadachowska A., KaJtoch $€$. \& LachowsKa D. 2011: Genetic diversity of Philaenus spumarius and P. tesselatus (Hemiptera, Aphrophoridae): implications for evolution and taxonomy. - Syst. Entomol. 37: 55-64.

MaryańsKa-NadachowsKa A., Kuznetsova V.G., LachowsKa D. \& Drosopoulos S. 2012: Mediterranean species of the spittlebug genus Philaenus: Modes of chromosome evolution. J. Insect Sci. 12: 54.

Monti V., Manicardi G.C. \& Mandrioli M. 2011: Cytogenetic and molecular analysis of the holocentric chromosomes of the potato aphid Macrosiphum euphorbiae (Thomas, 1878). Comp. Cytogenet. 5: 163-172.

Perepelov E., Bugrov A.G. \& Maryńska-Nadachowska A. 2002: Constitutive heterochromatin in karyotypes of two Cicadidae species from Japan (Cicadoidea, Hemiptera). Folia Biol. (Kraków) 50: 217-220.

Sahara K., Marec F. \& Traut W. 1999: TTAGG telomeric repeats in chromosomes of some insects and other arthropods. - Chromosome Res. 7: 449-460.

Seabra S.G., Pina-Martins F., Marabuto E., Yurtsever S., Halkka O., Quartau J.A. \& Paulo O.S. 2010: Molecular phylogeny and DNA barcoding in the meadow spittlebug Philaenus spumarius (Hemiptera, Cercopidae) and its related species. - Mol. Phylogenet. Evol. 56: 462-467.

VítKová M., Král J., Traut W., Zrzavý J. \& Marec F. 2005 : The evolutionary origin of insect telomeric repeats, (TTAGG) ${ }_{n}$ - C Chromosome Res. 13: 145-156.

Vitturi R., Lannino A., Mansueto C., Mansueto V. \& Colomba M. 2008: Silver-negative NORs in Pamphagus ortolaniae (Orthoptera: Pamphagidae). - Eur. J. Entomol. 105: $35-39$.

Warchalowska-Śliwa E., Grzywacz B., MaryańsKa-NadaChowska A., Karamysheva T.V., Rubtsov N.B. \& Chobanov D.P. 2009: Chromosome differentiation among bisexual European species of Saga (Orthoptera: Tettigoniidae: Saginae) detected by both classical and molecular methods. - Eur. J. Entomol. 106: 1-9.

Whiting M.F., Carpenter J.C., WheEler Q.D. \& Wheeler W.C. 1997: The Strepsiptera problem: phylogeny of the holometabolous insect orders inferred from $18 \mathrm{~S}$ and $28 \mathrm{~S}$ ribosomal DNA sequences and morphology. - System. Biol. 46: 1-68.

Received August 29, 2012; revised and accepted March 29, 2013 